were normal. The kidneys were both enlarged, almost symmetrically so. They showed a lobulated appearance, with large areas of projecting pale cortex. On section the pale areas involved the external rind of the cortex and the intermedullary areas. The medullae and pelves of the kidneys were normal. The capsules were not adherent.

\section{Microscopical Examination}

Sections from the anterior tumour mass showed a glandular appearance, but no apparent division into cortex and medullary regions, as in the normal thymus, and with a distinct absence of Hassall's corpuscles. The main part was composed of round cells about the size of small lymphocytes, with deeply staining fragmented nuclei and a small amount of clear protoplasm. Meagre supporting fibrous tissue showed the presence of a number of branched reticulum cells. In addition, there were occasional small lymphocytes, granular leucocytes, and plasma cells. Blood vessels were not numerous.

The capsule of the kidney appeared normal. Immediately underneath it was an area of marked cellular infiltration, consisting of cells like those which were most abundant in the mediastinal growth. A few small lymphocytes and some typical stroma cells of thymius character were also seen. The glomeruli and the cortical tubules were set in a stroma which was densely packed with those cells, and a few of the glomeruli were infiltrated by them. The infiltration was confined chiefly to the region of the cortex, the medullary portion being for the greater part free. Some extravasated blood was seen in some of the tubules, and there was cloudy swelling of the epithelium. The effect of the tumour-cell infiltration was to compress and obliterate a number of the tubules.

The sections of the heart showed a round-celled infiltration between the muscular bundles, limited to the superficial region, and not extending any distance into the substance of the muscle. Definite loss of striation of the muscle cells was apparent. An area of the collapsed lung which was adherent to the tumour mass showed some cellular infiltration to be present, but, as in the case of the heart, it was only the adjacent alveoli that were affected, the collapse beyond being probably due to blockage of a bronchus. Sections of the glands showed very definite subcapsular spread of the tumour cells, while deeper down they were grouped round the lymph channels.

Microscopical examination of the tumour showed the characteristics of a round-celled sarcoma, differing from the lymphosarcoma of glandular type in size and staining property of the cell. The individual cells were for the most part of spherical shape, with fairly large-sized and deeply staining nuclei and small amounts of surrounding protoplasm. Some of the cells tended towards the short columnar type, but this was not a marked feature of the growth. The cells were arranged in dense groups with a small amount of fibrous tissue stroma, and vessels in the denser areas were few in number. No haemorrhages were seen. The reticulum of the thymus was definitely represented.

\section{COMmentary}

The question of lymphadenoma might be raised, but all the features of the case are against such an opinion. The possibility of a leukaemic enlargement of the thymus was weighed, and the involvement of kidney might favour such a view, but the absence of leukaemic infiltrations tends to negative the suggestion. On the other hand, no clinical examination of the blood had been made.

The tumour cannot be regarded as of the nature of a cancer of thymic origin derived from cells of the reticulum; nor can it be regarded as of the type of small oat-celled cancer described in cases of lung and mediastinal tumours by Barnard, and in thymic tumours by Duguid and Kennedy.

We have to acknowledge our indebtedness to Dr. Douglas Russell for permission to use the clinical report, Dr. Nesbitt for the history prior to admission to the infirmary, Dr. Jackson Wilson for the use of the $x$-ray plate and report, and Dr. John Anderson for the post-mortem report and the material studied, and for his advice and assistance.

\section{VARICELLA IN OLD AGE}

\author{
BY
}

J. D. ROLLESTON, M.D., F.R.C.P.

MEDICAL SUPERINTENDENT, WESTERN HOSPITAL, LONDON COUNTY COUNCIL

Until the beginning of the present century varicella was regarded almost exclusively as a disease of childhood ; this can be seen from the statements of Eichhorst, Gee, Gregory, Moore, von Jürgensen, and Thomas. Undoubtedly this belief was in part responsible for the factwhich I have mentioned elsewhere-that numerous cases of varicella were erroneously certified as small-pox during the epidemic of that disease in 1901-2. According to the late Dr. Wanklyn, whose assistant I was at that time, no less than 16.7 per cent. of the 300 cases of chicken-pox sent to the receiving station at South Wharf during the epidemic with the certificate of small-pox were over 18 years of age. Several articles were subsequently published recording cases of varicella in adults, but all the writers were agreed as to its rarity in old age. Von Genser, for instance, states that of 29,250 cases of varicella notified in Vienna from 1894 to 1900 inclusive, only six were over 50, four being 51 and 55 , and one each between 56 and 60 and 61 and 65 . MacCombie, who had a remarkably extensive experience of acute exanthemata in various London fever hospitals, stated in 1906 that he had seen only seven cases of chicken-pox in persons over 30 , one of them being in a woman aged 71 . Writing in 1928, Schamberg and Kolmer stated that 49 was the most advanced age at which they had seen a case of the disease. In a remarkable epidemic of varicella recently reported by De Decker at Kipushi in the Belgian Congo the majority of the cases occurred in adults, though no mention is made of any aged persons.

During the period January 1st, 1926, to September 30th, 1932, twenty-nine cases of chicken-pox in patients aged 18 and upwards were admitted to the Western Hospital, and three occurred in members of the staff-namely, in two nurses aged 20 and 35 and in a wardmaid of 18 . Of the twenty-nine patients only three were over 30-two men aged 31 and 64 respectively, and a woman aged 76 . The man aged 64, in whom the diagnosis of chicken-pox had been confirmed by Dr. Wanklyn, was one of a series, to which I have referred elsewhere, of five fatal cases of the disease which have come under my observation during the last thirty-two years. $\mathrm{He}$ was an alcoholic and debilitated subject, who was admitted to hospital with a copious eruption of varicella complicated by bronchopneumonia and albuminuria, and died three days later. The necropsy showed bronchopneumonia of both lungs, a large fatty and dilated heart, and cirrhosis of the liver.

I was asked on June 25 th, 1932, to see the woman aged 76 in my capacity as one of the small-pox consultants to the London County Council, because her age and the severity of her illness had suggested the possibility of small-pox. The distribution of the lesions, however, and their size, shapc, and multiformity, as well as the history of their appearance on the first day of disease, indicated chicken-pox. The diagnosis, moreover, was subsequently confirmed by a history of exposure to the disease within the previous fortnight at a hospital where she had been under treatment by deep $x$-ray therapy for lymphosarcom?. On admission to the Western Hospital there was considerable constitutional disturbance, and the temperature was $102^{\circ}$. The presence of lymphosarcoma was indicated by enlarged glands in the neck, axillae, and groins. In addition to its typical appearance and distribution elsewhere the eruption of chicken-pox was confluent over the parts of the left side of front and back of the chest and left arm, where she had undergone deep $x$-ray therapy. The temperature became finally settled on the third day after admission, and there was a rapid improvement in the general 
condition. The lesions in the area where the eruption was confluent showed some tendency to ulcerate, but.ultimately complete healing took place and the patient was discharged on July 30th without any complications having occurred. There also appeared to be some diminution in the size of the enlarged glands in the axillae at the time of her discharge.

As far as I have been able to ascertain from a fairly extensive investigation of the literature, this patient appears to be the oldest one in whom varicella has occurred, though doubtless older persons have been attacked without their histories having been reported.

Bibliography

De Decker: Bull. Méd. de Katanga, 1932, ix, 10.

Gee, S. J.: Reynold's System of Medicine, 1866, i, 523.

Von Genser, T.: Wien. med. Woch.. 1903, liii, 124

(iregory, G.: Lectures on the Eruptive Fevers, 1843, p. 227.

Von Jürgensen, T.: Nothnagel's Encyc. Pract. Med., Varicella, 1902.

MacCombie, J.: Allbutt and Rolleston's System of Medicine, 1906 ii, Pt. 1, p. 475

Moore, T. 1, p. 475. p. 125 .

Rolleston, J. D.: Acute Infectious Diseases, 1929, pp. 346, 357.

Schamberg, J. F., and Kolmer, J.: Acute Infectious Dise'ase's, 1928 p. 301 .

Thomas, L.: Ziemssen's Cy'clop. Pract. Med., 1875, ii, 8

Wanklyn, W. M.: British Medical Journal, 1902, ii, 47.

\section{THE DESIGN OF DIRECT PEDICLE FLAPS} BY

Sir HAROLD D. GILLIES, F.R.C.S.

CHIEF PLASTIC SURGEON, MINISTRY OF PENSIONS HOSPITAL, ROEHANIPTON, ETC.

The purpose of this communication is to describe a simple technique for the accurate design and transference of a full-thickness pedicled flap from one part of a patient to another without danger to the blood supply. The use of the direct flap method instead of the tube pedicle type of graft is to be preferred wherever possible, because it reduces the number of essential operations to two, with an interval of two to three-weeks, thus shortening the period of stay in hospital very considerably.

The principle of the method is to imagine the operation completed and to reverse the steps of the procedure of transferring the flap, using as a model an exact jaconet or linen pattern of the defect to be covered. It is thus possible to arrive with speed and accuracy at the correct topographical origin of the flap to be cut from the donor area. Suppose that there is a rectangular area over the posterior surface of the elbow-joint to be covered by a direct flap taken from the side of the abdomen. After the usual pre-operative preparation of the patient and sterilization of the pattern, the elbow is flexed and approximated to the side, bringing the defect as close as possible to the donor area. The pattern is now fitted accurately to the defect. The assistant holds the lateral edge carefully in position while the medial edge is turned over on to the abdominal skin and held by the surgeon in the position which it naturally takes, so as to leave the intervening portion comfortably slack. The lateral edge of the pattern is. then released and the arm moved away from the side, while the surgeon smooths the remainder of the pattern over the abdomen. The skin outlined by the pattern is marked by scratching, and dissected up to form a flap, the attached side of the flap on the abdomen corresponding to the edge of the pattern first shifted to the body. It is necessary in some situations to allow enough extra at the base of the pedicle to ensure a sufficiently large area of the flap being sutured in position. After two to three weeks the attached end of the flap is divided and sutured into position on the arm. The line of division can be readily marked out by placing the pattern in position over it.
The advantage of the method will be realized in direct transfers from limb to limb, such as calf or ankle to opposite leg or thigh. It will be -found a great comfort to know that the flap will fit its new bed accurately without it having to be pulled into place by overstretching some portions or inserting stitches, which exert considerable tension. Gangrene and removal of stitches are thus largely avoided.

The same principle of reversing the operation is applicable in making the design for all tubed pedicle transfers, but is not quite so essential owing to the great mobility and vitality of these flaps.

\section{A PATIENT WITH FOUR URETERS}

OSWALD ADDISON, F.R.C.S.

SURGEON TO THE HOSPITAL FOR SICK CHILDREN, AND TO THE WEST LONDON HOSPITAL

(With Special. Plate)

A double ureter on one side is among the more common abnormalities of the urinary tract, and is not infrequently associated with a hydro-ureter or other congenital defect on the opposite side. The two ureters arise from separate pelves and commonly fuse at some part of their course, being seldom completely separate for their entire length. Most often they join shortly above the bladder, which they enter by a common orifice. The union may take place soon after leaving the kidney, a single ureter continuing to the bladder, though it may again bifurcate and enter the bladder by two openings.

Two ureters on both sides, each entirely separate through its whole length, with four separate openings into the bladder, is a condition so rare as to make such a case worth recording. There is no example of this condition in the museum of the Royal College of Surgeons, or in the muśeum at the Hospital for Sick Children, Great Ormond Street.

\section{History OF THE CASE}

A girl, aged 8 years and 11 months, had a first attack of pyelitis in June, 1928, lasting three or four weeks. She had similar attacks each year until August, 1931. Since then attacks have been more frequent. The main features of the illness were fever and increased frequency of micturition ; there was no pain.

The patient is rather pale, but of normal development. There is no abdominal tenderness. The lower pole of the left kidney is palpable.

\section{Special Investigations}

Blood urea was $29 \mathrm{mg}$. per $100 \mathrm{c} . \mathrm{cm}$. Urea concentration: before urea, 2.15; first hour, 2.55; second hour, 2.40; third hour, 1.40. Examination of a catheter specimen of urine showed: specific gravity, 1020 ; turbid ; alkaline ; fair number of leucocytes and organisms, an occasional bladder cell, and a few amorphous phosphates. Culture of the specimen resulted in a profuse growth of $B$. coli.

$X$-ray photographs (see Plate) taken after the injection of $13 \mathrm{c} . \mathrm{cm}$. of uroselectan reveal the presence of two pelves to each kidney, opening into separate ureters. The lower pelvis on the right side is slightly dilated, but the calyces appear normal. The other three pelves are not dilated. The two ureters on the right side can be traced separately as far as the bladder. On the left side the shadows overlap, and only a single shadow can be traced to the bladder.

On cystoscopic examination (five-ounce distension) the following points were noticed: Bladder surface was normal. Two gaping ureters were seen on right side at same level. On the left side two openings were seen, the outer one small and retracted at a slightly higher level than the median opening, which appeared as a narrow slit. Indigo-carmine (1 c.cm.) was given intravenously, and showed in good colour in nine minutes, with a strong efflux from the outer ureter 